easily be made, if it were thought advisable.) The movable part of the frame is marked with the names of the months, and each month it is turned slightly on its axis so as to bring the name of the new month opposite a mark on the stationary part of the frame. Fig. 1 shows the instrument inclined for the month of October in latitude $15^{\circ} \mathrm{S}$., the north being to the right of the picture. The shadows show that the rays of the sun are striking the tubes approximately at right angles. It is, of course, necessary to mark the names of the months on the instrument according to the latitude in which it is to be used.

It is easy to show the importance of a correct exposure of the tubes by exposing a second pair in the vertical position at the same time.

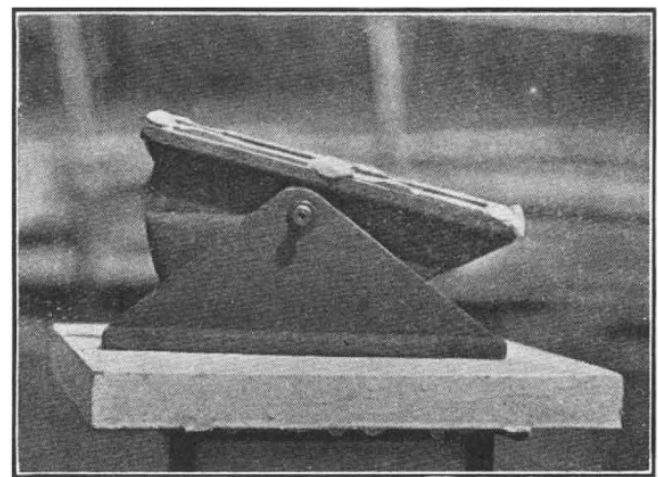

Fra. 1. Frame for exposing acetone methylene blue tubes.

My brother suggests the following alternative to my method of exposure. The tubes could always be exposed parallel to the axis of the earth, and a correction applied to the resulting figures to compensate for the varying obliquity of the rays during the different months of the year. Another plan would be to use spherical instead of tubular containers for the acetone methylene blue.

The expedition to the New Hebrides was supported by the University of Oxford, the Royal Society, the Royal Geographical Society and the Percy Sladen Trust. Ultra-violet light observations are still being made in the New Hebrides by members of the expedition. All the meteorological results will be published in full when a year is complete.

University Museum,

JOHN R. BAKER.

Oxford.

June 15.

\section{New Features of the Nitrogen Afterglow}

A sTUdy has been made of the nitrogen afterglow formed by passing nitrogen containing 0.25 per cent of oxygen through an uncondensed discharge produced by a 25,000 -volt transformer.

For the same type of discharge tube at $0^{\circ} \mathrm{C}$. the relations for velocity, pressure, and voltage are quite similar to those found for hydrogen afterglow by Van Cleave and Grubb ${ }^{1}$. When the critical voltage is reached, a greenish yellow glow appears in great intensity. At certain adjustments of pressure, velocity, and voltage, the afterglow shows many of the colours of the aurora. These colours are all visible at the same time, but at different distances from the discharge, the blue being the farthest removed. If the discharge tube is immersed in a bath at $30^{\circ} \mathrm{C}$. , the glow disappears, but if the temperature is lowered to $-20^{\circ} \mathrm{C}$., the glow is intensified.
The spectrum in the visible consists of first positive, second positive, first negative and nitric oxide bands. A line appears at $\lambda 5577$ which confirms the observation by J. Kaplan ${ }^{2}$. The plate also shows a first negative band at $\lambda 4780$ which is not reported by T. R. Merton and J. G. Pilley ${ }^{3}$. This band appears to be $\lambda 4779$ observed in the aurora by Vegard ${ }^{4}$. Other bands of the first negative system are superimposed upon the $\beta$ bands, which results in a different order of intensity than reported by Johnson and Jenkens ${ }^{5}$. The band $\lambda 4059$ of the second positive system is also quite intense.

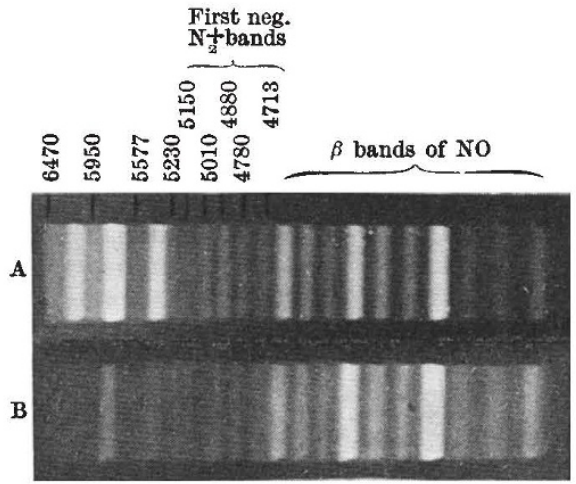

Fra. 1. A : Nitrogen afterglow ; primary 50 volts, pressure $10 \mathrm{~mm}$., flow 4 litres/hour. B: Afterglow in nitrogen with $0.01-0.05$ per cent sulphur. d litres/hour.

The upper spectrogram of Fig. 1 shows the bands of the afterglow taken under conditions such that the afterglow showed traces of green and blue. The lower spectrogram shows the bands of the afterglow with 0.05 per cent of sulphur dioxide added to the nitrogen before passing the gas through the discharge. The alpha and the first negative bands are considerably quenched while the beta bands are enhanced.

If the nitrogen is bubbled through concentrated sulphuric acid before passing through the discharge, the yellow afterglow is replaced by a blue glow. The blue glow shows a few of the prominent beta bands in the violet and a continuous spectrum in the blue. This is a very striking proof that bubbling a gas through concentrated sulphuric acid contaminates the gas with oxides of sulphur.

Details of this work will appear in a subsequent publication.

Chemistry Department, H. A. JoNES.

University, Saskatchewan.

A. C. GrubB.

NATURE, 132, 1001, Dec. 30, 1933

Phys. Rev., 33, 154; 1929.

Phil. Mag., 50, 195; 1925.

Phil. Mag., 46, 198; 1923.

Phil. Mag., 2, 621 ; 1926.

\section{Production and Planning}

To the now rapidly growing number of students of monetary reform, the leading article of July 7 will appear to be profoundly unscientific.

The abundance which is at present being produced below cost, and the outstripping of demand by production of the primary commodities, are viewed as phenomena not of over-production, but of underconsumption.

Real wealth is a matter of goods and services- 